\title{
La comunicación y periodismo ejercidos por Leonidas Proaño para el cambo social
}

\section{Communication and journalism exercised by Leonidas Proaño for social change}

\author{
Julio A. Bravo Mancero ${ }^{1 *}$, Fermín Galindo $\operatorname{Arranz}^{2}$ y Ramiro Ruales Parreño ${ }^{3}$ \\ ${ }^{1}$ Universidad Nacional de Chimborazo \\ ${ }^{2}$ Universidad Santiago de Compostela \\ ${ }^{3}$ Universidad de La Habana \\ *jbravo@unach.edu.ec
}

DOI: https://doi.org/10.26871/killkana_social.v2i3.331

\begin{abstract}
Resumen
El presente estudio, de tipo comunicacional tiene como objetivo: Determinar los elementos discursivos utilizados por Leonidas Proaño para la consecución de la transformación social. La metodología aplicada fue de tipo cualitativo; utilizó como técnicas la entrevista cualitativa y el análisis de contenido; los resultados visibilizaron el trabajo comunicativo y periodístico, la interrelación e interacción con sus audiencias, los efectos de los mensajes, las categorías y subcategorías discursivas utilizadas. Proaño, obispo ecuatoriano que, entre 1954 y 1988 lideró los procesos de cambio social para los indígenas de las provincias de la región central; utilizó como herramientas la comunicación y el periodismo, a partir de espacios formales e informales que fortalecieron la aplicación de su método Ver, Juzgar y Actuar, que buscaba: el conocimiento de su realidad, la toma de conciencia, el cambio de actitud y la resolución de los problemas que les aquejaban a este grupo de personas, en su mayoría analfabetos y trabajadores de las grandes haciendas. Fue interlocutor gracias al diálogo permanente, en distintos escenarios que tuvo con los indígenas ecuatorianos.
\end{abstract}

Palabras clave: Leonidas Proaño, comunicación, periodismo, transformación social.

\begin{abstract}
The present study, of communication type it has as aim: To determine the discursive elements used by Leonidas Proaño for the attainment of the social transformation. The applied methodology was of qualitative type; there used as technologies the qualitative interview and the analysis of content; the results visibilizaron the communicative and journalistic work, the interrelationship and interaction with his hearings, the effects of the messages, the categories and discursive used subcategories. Proaño, Ecuadoran bishop that, between 1954 and 1988 he led the processes of social change for the aborigens of the provinces of the central region; the communication and the journalism used as tools, from formal and informal spaces that strengthened the application of his method To see, To judge and To act, that was searching: The knowledge of his reality, the capture of conscience, the change of attitude and the resolution of the problems that were afflicting this group of persons, in the main illiterate and workers of the big household tasks. He was a speaker thanks to the permanent dialog, in different scenes that it had with the Ecuadoran aborigens.
\end{abstract}

Key words: Leonidas Proaño, communication, journalism, social transformation.

\section{Introducción}

\subsection{La puesta en escena}

Ecuador en la época de Leonidas Proaño estuvo caracterizado por la ruralidad; la población en su mayoría se concentraba en el campo y era indígena. Las condiciones en las que habitaban eran deplorables; hacinados en las haciendas trabajaban como husasipungueros y el producto de su esfuerzo servía para enriquecer a los terratenientes. La iglesia también estaba entre los latifundistas y entre quienes explotaban al indio. Muy joven, desde que fue ordenado sacerdote mostró su inclinación por la comunicación y el periodismo, esta motivación hizo que, en su tierra natal en la década del 40, Ibarra fundara tres periódicos: Cuadrilátero, La Verdad y Granitos de Trigo.

Nombrado Obispo de Riobamba, en 1954, y ya en funciones conoció la realidad de los indígenas que permanecían siglos en medio del abandono y la marginación, en el campo y en los sectores urbano-marginales de la capital de la provincia que, se encuentra a dos horas y media 
de Quito. Ya en funciones repartió las tierras eclesiales a cooperativas comunitarias agrícolas, preludio de la primera reforma agraria en el país.

En Riobamba, revivió su pasión por el periodismo; fundó la revista Mensaje (1965), que se convirtió en el órgano de difusión de la Diócesis; más tarde llegaría Escuelas Radiofónicas Populares del Ecuador (1962), el motor para el proceso de alfabetización; el periódico Jatari Campesino (1965) con contenidos desde una perspectiva laica; y radio Promoción (1972) como el eje para las acciones encaminadas al desarrollo y la capacitación de los líderes comunales; la creación de los nuevos medios en una provincia con el 90 por ciento de población indígena constituyeron un hito para una persona vinculada con la religión pero con vasta experiencia comunicacional y periodística.

Iniciar con el proceso de cambio social demandó acciones de tipo comunicativas; proximidad con la gente, como aprendió de sus padres, de niño, en Imbabura. El diálogo le abrió puertas y le proporcionó información, sobre lo cotidiano de las personas. El tratamiento comunicacional y periodístico del cambio social como mecanismo para la mejora de las condiciones de vida de las personas, no es un hecho reciente.

Entre 1954 y 1988, como obispo y Presidente de la Pastoral Indígena, desarrolló estrategias de acción a favor de la transformación de los indios de las provincias de la región central; Don Leonidas utilizó como herramientas la comunicación y el periodismo, a partir de espacios formales e informales que fortalecieron la aplicación del método Ver, Juzgar y Actuar, creado por el padre Cardijn en Europa en 1915 y aprendido en 1930 en la Juventud Obrera Católica, que buscaba: el conocimiento de su realidad, la toma de conciencia, el cambio de actitud y la resolución desde adentro de los problemas que les aquejaban a este grupo de personas, en su mayoría analfabetos y trabajadores de las grandes haciendas.

Las visitas a las comunidades y la cercanía con la gente le hicieron que el obispo constatara la realidad de estas personas; se asemejaba a lo descrito por Eduardo Galeano (1971, p. 62) "los indios debían al encomendero servicios personales y tributos económicos, no era mucho el tiempo que quedaba para introducirlos en el cristiano sendero de la salvación".

El fundamento teórico de este estudio está en las propuestas realizadas por Barbero (2003), Baudrillard (1984), Canaval (2000), Dubravcic (2002), García (2008), Marcuse (1992), Galeano (1971),Herrera (1992), Igartúa \& Humanes (2010), Kaplún (1983), Marcuse (1973), Muñoz (2011), Ossandon (1988), Proaño 1974), Rizo (2012), Serrano (1982); y, en los hallazgos de la investigación doctoral en Comunicación e Información Contemporánea de la Universidad Santiago de Compostela.

Se planteó como objetivo de investigación Determinar los elementos discursivos utilizados por Proaño para la consecución de la transformación social. Se identificaron como variables la comunicación y el periodismo utilizadas por Leonidas Proaño; y el cambio social provocado a favor de los campesinos ecuatorianos.

La metodología empleada es de tipo cualitativo: como técnicas se utilizó el análisis de contenido para 94 ediciones de la revista Mensaje; 55 guiones del programa radiofónico Hoy y mañana, difundido los viernes de 15:00 a 16:00 por Escuelas Radiofónicas Populares del Ecuador; ocho ediciones del periódico Jatari Campesino; 21 Discursos y 50 homilías pronunciados por el religioso. Y la entrevista cualitativa a 11 expertos en el tema. Los resultados identifican las categorías discursivas empleadas, las temáticas utilizadas y los efectos que intentó tener para procurar un cambio de actitud y que alcancen el estatus de seres humanos; y para el cambio social.

Identificar los puntos de interés comunes para los habitantes de una provincia deprimida como la de Chimborazo, los espacios de atención y de intervención, la construcción a través del diálogo de nuevas escenografías que fortalezcan su identidad, la recuperación de valores, alcanzar la superación mediante campañas de alfabetización, educación y formación, y cómo, para estos seres humanos la praxis viviente de la palabra les permitió recuperar el valor de la comunidad, le entrega pertinencia al estudio.

\section{Marco Teórico}

\subsection{La perspectiva de la comunicación}

La concepción comunicacional para la presente investigación tiene como producto la revisión de las propuestas realizadas por expertos, desde lo histórico-contemporáneo, con el fin de demostrar que las acciones de Taita Proaño se mantienen intactas: la aproximación a los indígenas usando formas y recursos comunicativos que fueron pioneros para la época, como se presentará en los resultados.

La Teoría de la Comunicación, expresada por (Serrano, 1982, p.18) se asemeja a los procesos desarrollados por Leonidas Proaño y su interés por resaltar la importancia de "algunos seres vivos de relacionarse con otros seres vivos intercambiando información". El asidero se evidencia en la proximidad con los indígenas de las comunidades de la provincia de Chimborazo; a través del diálogo conoció sus carencias, los escuchó con atención y encarnó una problemática invisibilizada durante siglos. Una manera de defender su proximidad con las personas es haber pasado de la comodidad de quien escucha a convertirse en lo que el profesor español denomina Actor de la comunicación.

La comunicación por ser una forma de interacción, supone la participación de al menos dos Actores. En la situación comunicativa, los Actores ocupan posiciones distintas y en el transcurso del proceso comunicativo desempeñan funciones diferentes (Serrano, 1982, p.19).

Jürgen Habermas (1987) desarrolló la Teoría de la acción comunicativa y en ella profundiza sus estudios sobre la realidad social delineando dos formas de interacción: el trabajo y la comunicación, porque los actos comunicativos 
cumplen una función de integración y de mantenimiento del sistema social. Sin embargo, la propuesta de Marta Rizo (2012, p.21) demuestra que lo importante de la comunicación ejercida por Proaño es la búsqueda de esa capacidad para relacionarse con los demás, pero, tomando el rol de actor. Esta perspectiva asumió que "la función básica de la comunicación humana es desarrollar relaciones, más que intercambiar información". Dejó de lado la unidireccionalidad comunicativa y la reemplazó por la doble vía porque le garantizaba que un "abordaje de la comunicación debe tomar en cuenta esta diversidad de perspectivas y acercamientos", (s.f., p.1).

Al respecto, las formas relacionarse con los indios y de obtener información como resultado de horas de conversación y escucha en su despacho y en las comunidades, pueden ser de un enfoque subjetivo, aspecto enfocado por Herbert Marcuse en 1929. "El subjetivismo, cuanto postura ontológica, tiene que refugiarse en la cada vez más evanescente concepción abstracta del ser de lo real", (Muñoz, 2011, p.3). Debe entenderse, además, que el conjunto de relaciones entre seres humanos (actores del proceso de comunicación) proyectan una imagen, la que es expuesta desde tres niveles por Baudrillard (1984): la imagen representa la realidad; la imagen enmascara la realidad; en la realidad no existe solo símbolos. Y eso precisamente reflejó los procesos de interacción del prelado.

Descubrió que aproximándose a la gente había un nuevo tipo de interacciones, alcanzó una nueva dimensión comunicativa; y si ésta marcó sus límites lejos de las formas tradicionales, entregando a la gente común la importancia que merecía, la ubica en el umbral de una nueva perspectiva desde donde se identifican los aspectos cotidianos identitarios; $y$, si se privilegia a lo popular, desde lo comunicacional, como generador de nuevas apuestas, estamos frente a otros escenarios de intervención.

Este primer intento de comunicación popular, describe Fernando Ossandon (1988, p.50)

Ante todo, la comunicación popular ya es ün dato"de la realidad. Existe un amplio conglomerado de prácticas de elaboración y/o consumo de mensajes que provienen del pueblo y se dirigen prioritariamente a él. En ocasiones, se dirigen a la sociedad en su conjunto Adquieren formas e intensidades diferentes. según el país o sector en el cual se originan.

Es necesario re-insistir en la afirmación de Dubravcic (2002) que la comunicación popular se distingue como una práctica de intercambio cultural y simbólico entre actores sociales de las más diversas características culturales y cuyo proceso de recepción se define más bien como apropiación determinada por tales diferencias. Para Mario Kaplún (1983, p. 40) esta tipología está unida al cordón umbilical de la comunicación alternativa porque se encontró con "Carentes de condiciones para enfrentar a las grandes redes masivas, sin peso para incidir en las políticas nacionales de comunicación". Y también se diría que se enfrentó a un nuevo espacio para ejercer el periodismo, también atado con lo popular.

El aparecimiento en la década del sesenta de la radio popular en el Ecuador, creada por Leonidas Proaño con fines alfabetizadores de la gente del campo y de los sectores urbano-marginales impulsó nuevas escenografías para el abordaje de otro tipo de contenidos más próximos a la gente que no tenía espacio en los medios tradicionales.

García, D. (2008, p.127) describe:

En el año 1962, Monseñor Leonidas Proaño decide fundar las Escuelas Radiofónicas Populares de Ecuador (ERPE). Él, obispo de los Indígenas y los Pobres, consideraba que a la pobreza había que combatirla con educación y para llegar a los indígenas que se encontraban entre los páramos del Chimborazo, nada mejor que una radio.

Pronto el esfuerzo se propagó por todos los sectores porque para implementar una parrilla de programación requería el recurso humano suficiente; fue necesario entonces la formación de reporteros populares, auxiliares para el acompañamiento de las actividades educativas, técnicos en agricultura y ganadería que gusten de la radio para producir contenidos y transmitirlos en emisiones del amanecer. Incluso el mismo Proaño produjo, dirigió y condujo su programa radiofónico (Hoy y mañana), espacio dedicado a la educación, socialización y la práctica periodística.

Se estima que durante 1962-1972, 18 mil indígenas fueron alfabetizados motivando de esta manera nuevas formas de vida cotidiana, de interacción e interrelación, lo que se definiría como el cambio social para los habitantes del campo y la ciudad.

El cambio social es el resultado de la intervención formal en territorio con el compromiso de los actores que, asumiendo su rol encuentran mejores condiciones de vida individuales y colectivas. Canaval (2000, p.37) sostiene que "se aplica a una gran variedad de fenómenos y puede llegar a ser ambiguo o vago como resultado del uso convencional, amplio y variado".

"Es un concepto multidimensional, que es visto como un proceso", (M., 1992, p.657), pero este proceso no es aislado porque está integrado por el conjunto de voluntades que tienen un fin común: mejorar el nivel de vida de los integrantes de un colectivo. Es esta afirmación la que evidencia el objetivo trazado por Leonidas Proaño: cambiar la vida de los indígenas ecuatorianos con la comunicación y el periodismo como herramientas.

\section{Metodología}

En la investigación, el método empleado fue de tipo cualitativo porque "en las disciplinas de ámbito social existen diferentes problemáticas, cuestiones y restricciones que no se pueden explicar ni comprender en toda su extensión desde la metodología cuantitativa”, (López, 2002, p.168). Se emplearon dos técnicas: el análisis de contenido y la entrevista cualitativa. 
El análisis de contenido que, "es un conjunto de instrumentos metodológicos, aplicados a lo que él denomina como discursos (contenidos y continentes) extremadamente diversificados", (Bardin, 1986, p.7). Y, para Berelson (1952), es una técnica de investigación que pretende ser objetiva, sistemática y cuantitativa en el estudio del contenido manifiesto de la comunicación. Se desenvolvió en varias etapas que consistieron en la recogida de información aplicación del instrumento (matriz de análisis, diseñada por los investigadores), selección y valoración, jerarquización, análisis e interpretación, jerarquización y presentación de resultados.

Y la entrevista cualitativa o de profundidad que para Kirk \& Miller (1986) son un fenómeno empírico, definido por su propia historia. Steinar Kvale (1961, p.8), añade que buscan que una persona regrese en el tiempo para documentar que "la conversación es una forma antigua de obtención de conocimiento". Y, Mills, (1959) considera que esta técnica abre la puerta a una sociología de la entrevista, que en tanto ejercicio intelectual no se completará hasta poner en relación los elementos históricos, biográficos y de estructura o cambio social.

Con el cuestionario como instrumento se obtuvo información de testigos vivenciales de la obra del religioso. Todos tuvieron una relación directa a través de la vida pastoral, la comunicación, los procesos de formación obrera y el cooperativismo. Sus aportes son relevantes por los datos que proporcionan y cómo inciden en los resultados de la investigación.

\section{Análisis y discusión de resultados}

Cada uno de los elementos encontrados hacen énfasis en el desarrollo del método de Proaño (1974) para la toma de conciencia dentro de un proceso que, demandó: primero de un acercamiento a los lugares donde habitan las personas; y, después observados y recogidos en las visitas pastorales, audiencias en el Palacio Episcopal de Riobamba, en mingas, en encuentros informales con la gente pobre y los indígenas; $y$, tercero difundidos. "Durante un acercamiento se va obteniendo una gran lista de problemas de la comunidad", (p. 63).

Todo acercamiento y la posterior intervención son importantes, desde la perspectiva de Proaño, porque brindan la posibilidad de efectuar una transfusión de visiones sobre la realidad y ellas deben permitir evidenciar ese conjunto de problemas que están en el entorno y que necesitan ser analizados, reflexionados y transformados.

a) Análisis de contenido: Aplicado a 55 guiones del programa Hoy y mañana, difundido en la década de los 70 hasta inicios de los 80, por Escuelas Radiofónicas Populares del Ecuador ${ }^{1}$. A

\footnotetext{
${ }^{1}$ Escuelas Radiofónicas Populares del Ecuador fue uno de los medios de comunicación fundados por el Obispo de Riobamba. Para desarrollar su proceso alfabetizador, de evangelización y toma de conciencia, el 19 de marzo de 1962, oficialmente inicia sus transmisiones. Desde el principio (1959) con la idea en su cabeza, Proaño y dos sacerdotes, visitó radio
}

la revista Mensaje $e^{2}$ que, tuvo 94 números durante siete años (1955-1961). Al periódico Jatari Campesino $^{3}$ que circuló por primera vez en 1964 con una periodicidad bimensual (8 ejemplares). A 21 homilías y 50 discursos cortos pronunciados en distintas ciudades de Ecuador y de América. Se obtuvieron categorías y subcategorías semánticas que englobaron los niveles de discursividad.

Por las condiciones de la época y lo apartado de las comunidades, la ausencia de caminos vecinales, el déficit de sacerdotes (solo 62 para toda la diócesis con un 92 por ciento de población indígena) surge otro de sus anhelos: formar sacerdotes indígenas. La barrera del idioma impedía el acercamiento y el diálogo como herramienta para la toma de conciencia; esto lo comprobó cuando fue a anejos olvidados, no podía confesar a sus fieles porque no entendían el castellano y él tampoco el kichwa; pidió colaboración de los sacerdotes redentoristas afincados en la iglesia de San Alfonso. Esto volcaría su mirada a lo que ya se había tratado en la Conferencia de Medellín de 1968: era necesaria una verdadera Iglesia Popular que llevara el mensaje a quienes nunca lo recibían. Y lo mismo se evidenciaba en los sectores ubicados en la periferia de Riobamba. La realidad hizo que ponga en marcha su proyecto pastoral, revolucionario para la época; consistía en la creación del Seminario Menor e impulsar proyectos de promoción pastoral campesina.

Sutatenza en Colombia con el fin de observar cómo se atendía a los sectores campesinos mediante las ondas radiales. Convencido de que su proyecto podría funcionar en Ecuador, hizo hincapié en que una Radio Escuela para campesino ayudaría a devolverle la luz al sector indígena que vivía en las tinieblas. La Santa Sede hizo un aporte inicial de Usd 5.000, una tercera parte de los 13.230 dólares necesarios para la compañía Philips instalara un transmisor de $5 \mathrm{kw}$ y el equipamiento para la cabina. Pero seguía habiendo un déficit y sin doblegarse buscó en sus amigos del exterior la ayuda para hacer realidad su proyecto. Y lo logró.

${ }^{2}$ La revista Mensaje durante los siete años que circuló (15 de mayo de 1955 hasta agosto de 1961), fue el órgano oficial de la Diócesis de Riobamba a través del que se difundieron todos los aspectos relacionados con: actividades clericales, información religiosa de lo que ocurría en la Conferencia Episcopal Ecuatoriana y todas las parroquias del obispado, comunicación oficial (circulares episcopales, circulares diocesanas, decretos, exhortos y boletines), reseñas de la presencia del Prelado en la conferencias episcopales internacionales (Concilio Vaticano II, CELAM en Medellín y Puebla, reuniones de la Organización Mundial de Prensa Católica), un espacio fijo denominado De conversación con mis hijos para expresar los puntos de vista de Monseñor y también otros segmentos dedicados a la Legión de María, Catecismo, publicaciones de otras revistas religiosas. Al principio tuvo una periodicidad quincenal y terminó siendo bimensual. Cuando publicó la edición 94 cerró un ciclo de seis meses y luego dio el paso a la radio.

${ }^{3}$ Considerado por Leonidas Proaño con un medio complementario, de la radio, para su actividad alfabetizadora y concientizadora. Encontró el apoyo en la Misión Andina y otras organizaciones no gubernamentales. Él decía que de nada servía que les enseñara a leer y escribir a los indígenas si no tenían un medio en el que practicar lo que en clase recibía. En los momentos de mayor actividad llegó a tener un tiraje certificado de $10 \mathrm{mil}$ ejemplares, circulaba a nivel nacional, en tamaño tabloide. Su particularidad: el editorial aparecía en portada en castellano y kichwa, publicaba las cartas que le enviaban de todos los sitios del Ecuador y tenía espacios fijos para la mujer, agricultura, ganadería, educación, entretenimiento, deportes y amenidades. Siempre tuvo la estructura de un periódico. La portada y contraportada circuló a dos colores (algo revolucionario para la época en una provincia pequeña como Chimborazo). Al cabo de algunos años, por motivo de financiamiento se transformó en un folleto impreso en mimeógrafo y fue su declive y desaparición. 
Gavilanes (1992, p.118) sostiene que,

Un diagnóstico de la realidad socio-económica, cultural y religiosa del campesinado de la provincia, se registra, ya en un documento del Obispado aparecido a finales de 1956 bajo el título de 'Proyecto de una labor de incorporación del indio a la vida civilizada'.

El diagnóstico y el documento resultante hablaba de entregar respuestas a los indígenas frente a su realidad, resolver los problemas desde adentro, entregarles oportunidades para que se preparen y puedan defenderse de la explotación, vencer la inequidad mediante una verdadera educación liberadora que abra sus ojos. Buscaba y se refería por primera vez a incorporar al indio a la vida civilizada, sin alcoholismo y lejos de la miseria.

Insiste Gavilanes (p. 119) en el diagnóstico situacional: el mundo indígena es explotado y analfabeto; el mundo urbano es de clase obrera artesanal; existe inconsistencia en las organizaciones de apostolado. Lo que le caracterizaba a Proaño fue la acción y pasó de los resultados de la investigación al planteamiento de los objetivos que, marcarían su paso por la Diócesis: formación pastoral de los sacerdotes; promoción de vocaciones; formación de maestros católicos; formación de núcleos de apóstoles, seglares, dirigentes sociales y líderes campesinos; creación del Instituto Diocesano de Pastoral; fundación del Normal para la formación de maestras católicas; creación de escuelas artesanales; creación de las comunidades eclesiales de base ${ }^{4}$; incremento de nuevas parroquias y creación de escuelas parroquiales, formación de movimientos cooperativistas, creación de talleres y comunidades de trabajo, misiones y catequesis, misión de religiosas lauritas.

Se miraba su llegada un nuevo horizonte para los indígenas del campo y los pobres de la ciudad pese a la oposición dentro y fuera de la iglesia. No faltaron las denuncias que incluso derivaron en agosto de 1976, en el Hogar Santa Cruz, en su apresamiento junto con otros obispos latinoamericanos, sacerdotes, religiosas, seglares y personas vinculadas con su actividad de concientización, acusados de subversivos.

Uno de los recursos para vencer la explotación y la marginación fueron los procesos de concientización. Él mismo explica a esta última como un despertar para autosituarse, para perfeccionar el mundo, para perfeccionar la sociedad, para perfeccionarse perfeccionando y realizando

\footnotetext{
${ }^{4}$ La experiencia al estar con la gente del pueblo, las visitas pastorales, las largas misiones que recorrían el largo y ancho de la Diócesis, la convocatoria de personas vinculadas con los problemas sociales, la catequesis y la acción social permitió que, especialmente, los fines de semana haya cientos de reuniones en los que se respondía, debatía y se aportaba, con el evangelio en la mano, las preguntas que el obipso enviaba como "tarea". Las acaloradas discusiones se hacían en medio de los grupos de trabajo y ahí fueron destacando algunas personas que empezaron a conducir los encuentros pastorales de toma de conciencia de su realidad. Pronto, se llamaron comunidades eclesiales de base. De base por el análisis, reflexión y acción frene a sus problemas; y por el proceso de formación para un trabajo bien apuntalado lejos de la centralidad y del confort del Palacio Episcopal.
}

la historia; es resultado de una conciencia crítica. Solamente puede vencerse toda muestra de explotación si se actúa en comunidad, pero para conseguirlo es necesario desarrollar una efectiva toma de conciencia, como mecanismo válido para encontrar las respuestas en el entorno, para definirse a sí mismo, para vincularse con el prójimo y para en conjunto actuar frente a las amenazas que están cerrando sus caminos. El religioso consideraba que Dios nos quiere juntos, no aislados en su proyecto para encontrar la salvación. ¿Qué significa toma de conciencia? ¿qué mecanismo debe utilizarse para hallarla? ¿qué nivel de involucramiento demanda?

Definía Proaño (1974, p.39),

La toma de conciencia es la facultad espontánea que tiene todo hombre, por el simple hecho de ser hombre, de percibir la realidad que le rodea, de darse cuenta de la existencia de las cosas, de los hombres y de sí mismo.

Entrar en toma de conciencia demanda cierta dosis de raciocinio y para eso es indispensable hallar las causas y consecuencias más bien inmediatas a los problemas, una vez situados en ellos. es decir, nos lleva a una inevitable acción y a vencer los obstáculos que están en el camino vestidos con el ropaje de un racismo que genera solamente exclusión. Sin embargo, existe un mecanismo que es la liberación: no puede hablarse de ella si el hombre no es capaz de amar, de superar su egoísmo y de entregarse al bien de los demás (p. 46). Insiste en trabajar juntos para caminar por la misma ruta que lleva hacia el cambio social.

El proceso de alfabetización permaneció hasta 1976 y a partir de allí nació el "Sistema de teleducación" como respuesta a las necesidades de los alumnos ya alfabetizados de querer obtener un programa educativo que les otorgara la primaria. Se diseña entonces un sistema a distancia apoyado por el Ministerio de Educación y que retaba a ERPE a emprender un nuevo proceso educativo desde la comunicación, (Ávalos, 2017, p.64).

En la ciudad y, como complemento a todas las otras actividades impulsadas, también se piensa en la formación integral de la mujer y se abre un Hogar de acogida en el cual jóvenes indígenas empiezan con su proceso de formación para que poco a poco el servicio de casa o servicio doméstico deje de ser la única opción en las que podían trabajar y se destierre esta forma de esclavitud moderna.

Otra vez en el campo, con el apoyo de la Organización Internacional del Trabajo (OIT), la Misión Andina empieza a cooperar en el Ecuador y precisamente en las comunidades deprimidas de esta provincia. Intervienen en procesos de educación, agro, formación integral de los campesinos. Proaño, en el número 80 de la revista Mensaje, de 4 de octubre de 1959, en De conversación con mis hijos, espacio en el que habitualmente escribe, no oculta su emoción al afirmar que:

He ido para bendecir cinco escuelas y asistir a su inauguración solemne (...). Como el perrito, co- 
mo el borreguito vivíamos hasta entonces, botaditos y olvidados. Ahora ya sabemos leer y escribir. Ahora ya tenemos escuela para que aprendan a leer nuestros hijos y para que aprendan a vivir como racionales. Ahora ya tenemos taller de carpintería, taller de mecánica. Y es que, para ellos, para los pobres indios, la escuela, el taller, el huerto y el camino comunal, el acercamiento de personas que se han preocupado por mejorar sus condiciones de vida les han abierto nuevos horizontes: los horizontes de la cultura, los horizontes de la vida social, los horizontes de una vida económica más estable y decente. $\mathrm{Y}$ es que todos estos horizontes deben constituir el paso ancho y cómodo hacia horizontes más luminosos: los que ofrecen la fe ilustrada, la religión mejor conocida y practicada, y Dios mejor conocido, amado y servido (pp. 176178).

Esta publicación empezó a circular casi diez años después que monseñor Proaño fuera nombrado Obispo de Riobamba. Una de sus primeras acciones fue devolver las tierras a quienes les pertenecía y levantó polvareda si recordamos que uno de los mayores terratenientes en la provincia era precisamente la iglesia. La devolución no fue individual sino a través de una cooperativa, acto que fuera considerado como un grave error por sus críticos y hasta seguidores; el poder pasó a nuevas manos que siguieron explotando a los más débiles. Es decir, el dominio sobre quienes labraban tuvo una variación pequeñita, pero de manos.

Este hecho es considerado formalmente como el primer intento de reforma agraria en el país que fue seguido en los posterior por la Junta Militar (1963-1965). Como se dijo en párrafos anteriores, incorporar al indio a la vida civilizada equivalía a poner en marcha la Granja Escuela Tepeyac y la Casa Hogar "Nuestra Señora de Guadalupe" regentada por las monjitas Lauritas, en la hacienda Monjas Corral. Para que el indígena se convierta en un motor para el desarrollo nacional necesitaba este tipo de accioness. Gavilanes (1992) indica que la granja se proponía la formación de promotores para el desarrollo rural campesino, formar cooperativas agrarias y educar líderes naturales para las comunidades; y para el segundo abrir el panorama de las jóvenes hacia otras áreas en las que puedan desenvolverse y no solo empleadas domésticas mal remuneradas y ultrajadas. Explica Proaño (1956, p.8) que, "no se trata de dar una cuadrita a cada individuo. Quiero que la parcelación se efectúe entre cooperativas para que sirva de provecho".

La misión estaba incompleta y esto hacía que se abra un nuevo frente, con la misma ambición del primero: formación de líderes campesinos para el campo social que equivalía a preparar la mentalidad del indígena para los cambios que traía el progreso, para que los afronte y pueda desarrollarse con ellos. En 1960, luego de un proceso de capacitación de cinco noches consecutivas, se funda oficialmente el Centro de Estudios y Acción Social (CEAS) cuyo facilitador fue el profesor de la Universidad de Lovaina y director de Acción Internacional de Desarrollo Cooperativo, Rudolf Reszohazy. Su presencia en el Ecuador y la conformación del equipo de trabajo significó de motivación para el despegue de la naciente organización, cuyos fines estaban claros

Los miembros del CEAS se hallan distribuidos en tres equipos: uno que se encargará de trabajar para el desarrollo de las cooperativas agrícolas; otro que se encargará de llevar adelante el funcionamiento de una cooperativa de crédito; y, otro que se encargará de propagar la doctrina y práctica del cooperativismo, Proaño (1960, p.81-82).

Los dos primeros trabajarían en el aspecto material y el tercero en lo espiritual, solo así el desarrollo sería en verdad integral. Esto motivó un cambio integral, vencer las injusticias y encontrar la armonía para los sectores abandonados a su suerte que pronto arrojó los primeros resultados.

Los discursos y las homilías estudiados corresponden a una etapa de Proaño como Presidente del Departamento de Pastoral Indígena del Ecuador, nombramiento solicitado por el Papa Juan Pablo II durante su visita al país en 1984; y, como candidato a Premio Nobel de la Paz, propuesto por Adolfo Pérez Esquivel. En estos años ha alcanzado la plenitud de su madurez religiosa y social, marcado por todas las circunstancias que tuvo que afrontar durante su obispado. Su padre, un tejedor de sombreros le inculcó desde muy niño, es su casa que fue la primera escuela que a los indígenas hay que amarlos, que son hermanos, hijos de Dios. Y de su madre, la proximidad hacia las mujeres campesinas y es orientación para el cuidado de la familia como eje de una sociedad injusta para ese tiempo.

La pedagogía del oprimido de Paulo Freire (1976) le guió hacia la práctica de una educación en verdad liberadora a favor de los desposeídos, primero haciendo que se reconozcan como seres humanos; que no están solos y que conviven con otras personas; y finalmente, que la palabra de Dios abre el camino de verdad, justicia, esperanza y amor. En cada intervención dentro y fuera de Ecuador estuvo entre niños, mujeres, ancianos, jóvenes, académicos, campesino, indígenas, obreros, religiosos, diplomáticos. Su rumbo nunca cambió.

b) Entrevistas cualitativas: se efectuaron a 11 personas que como se dijo estuvieron en contacto con el religioso; compartieron el camino andado desde diferentes instancias. Sus criterios son valiosos y aportaron información para la investigación. De ellos, para este trabajo y jerarquizados sus aportes, se escogió a siete.

Sus criterios son de peso y fue necesario dividirlos en tres categorías (comunicación, educación y evangelización) con el fin de procesar cada uno de los mensajes sobre el tema de la investigación. La siguiente tabla es un resumen de las expresiones de quienes, en determinada etapa de la vida del obispo, fueron parte de los equipos de trabajo o estuvieron próximos desde organizaciones e instancias. 
Conocer a su pueblo, descubrir cuáles eran los problemas que le preocupaban, hacer que reflexionaran sobre ellos y que buscaran la transformación desde el evangelio le motivó a que jamás se quedara estático, a estar moviéndose permanentemente, dice Juan Pérez, director de Escuelas Radiofónicas Populares del Ecuador.

Yo creo que no hubo un domingo que se quedara en la casa a descansar, sino que salía permanentemente. Y no eran unas salidas de turismo; eran unas salidas que tenían, yo creo tres acciones: la una, conocer la realidad escuchando la gente, ese siempre fue su llegada, se sentaba, conversaba, escuchaba, une elemento clave en todo lo que él desarrollaba, sentarse con la gente donde vivía, en el patio, en una loma a conversar. (Juan Pérez. Entrevista personal No. 1. 27 de julio de 2017)

Rubén Viñán sabe que el acto de escucha como mecanismo de enriquecimiento y registro, le hicieron a Proaño tomar nota de todo lo que veía y escuchaba. Esto le permitió tener conocimiento de causa de lo que acontecía en su Diócesis, qué hacer en la intervención que se hizo y comprender por qué ocurrían las cosas.

El indígena, sus dirigentes, los catequistas, en el tiempo de ERPE, los animadores siempre buscaban un mensaje de él. Cuál era su mensaje: saludar, escuchar, oír lo que los participantes, su pueblo le decía. Él siempre fue un gran comunicador. Suelta palabras y luego escucha, escucha, escucha. Y una que otra palabrita anota. Esa fue la comunicación con su pueblo. (Rubén Viñán. Entrevista No. 2. 31 de julio de 2017)

Cuando aprendieron a leer y a escribir empezaron a tener derechos, comenta Patricio Muñoz quien trabajó en el sistema de Teleducación y conoció de cerca a Proaño y la realidad de los indígenas; con educación ya no eran presa fácil de actos de discriminación, pero ese fue un proceso que tardó tiempo en llegar, que no fue inmediato.

Llegaba un indígena a una institución, a cualquier parte y era tratado de vos (...), y vos de dónde eres, y vos qué quieres, en un tono despectivo; en cambio, viene ahora un compañero del campo de las comunidades y se le dice cómo está, qué necesita, qué desea. (Patricio Muñoz. Entrevista No. 3. 15 de agosto de 2017)

Del lado de los trabajadores, el proceso de formación mediante la organización de centros educativos y del fortalecimiento de los gremios artesanales hizo que el respeto a los derechos fundamentales no sea una cuestión solo de papel; con instrucción y unidos era más difícil ser explotados, comentó la dirigente sindical Mariana Guambo.

Los empresarios tienen la obligación de practicar la verdad pagando bien a sus trabajadores, no explotándoles; los hacendados pagando bien a los indígenas, no robándoles. (Mariana Guambo. Entrevista No. 4.14 de agosto de 2017).
Romper las cadenas de la esclavitud fue una misión que siempre estuvo en la acción práctica del obispo. Pero ser esclavos en esa época tenía otros matices como lo señala Pedro Morales, dirigente cooperativista que se desarrolló junto a Taita Leonidas Proaño.

Él habría sido un permanente denunciante de esa realidad. Él siempre partía del hecho de que hay que romper esquemas de opresión, de esclavitud, de injusticias sociales para encontrar la liberación de los pobres. (Pedro Morales. Entrevista No. 5.18 de agosto de 2017)

$\mathrm{Su}$ preocupación fue por la construcción de una iglesia viva para los indígenas, una institución con la que se identifiquen, en la que puedan confiar. Pedro Torres recuerda cómo el obispo luchó hasta el final de sus días por entregarle dignidad al indígena.

Entonces todo eso de la iglesia indígena, teología indígena, pastoral indígena, inculturación, era una preocupación que él tenía y que eso no solo que le permitió proyectar el avance de la iglesia hacia los indígenas. (Pedro Torres. Entrevista No. 6. 27 de julio de 2017)

Para Estuardo Gallegos, el Evangelio le entregaba al indígena la fortaleza para liberarse de la opresión. Los siglos de dominación no habían terminado, pero empezaba a brillar una luz de esperanza. La intervención poco a poco se convirtió en una tarea impostergable.

Él se daba cuenta que la historia nuestra es la historia de los dominadores, es una historia de sufrimiento, de marginación y muchas veces de explotación pura y dura. Eso es contrario al espíritu liberador del evangelio. (Estuardo Gallegos. Entrevista No. 7. 12 de septiembre de 2017)

\section{Conclusiones}

La comunicación desarrollada por Leonidas Proaño fue horizontal con el diálogo como basamento; fortaleció la interrelación, interacción e intermediación en actividades concretas que se desarrollaban en las comunidades, durante las visitas pastorales a la Diócesis de Riobamba; y en las audiencias que se realizaban dos días de semana y en las que acudían a conversar con el religioso cientos de indígenas.

Cuando conformó el Frente de Solidaridad y la Comisión Permanente de los Derechos Humanos como organismos de asistencia ante la realidad político-social que vivía el Ecuador, desarrolló una línea de comunicación política desde la que intervino en conflictos de todo nivel que le permitió volver a involucrarse con la gente que sufría otro tipo de marginación y explotación en lo laboral.

Practicó el periodismo porque no solo fundó medios masivos, sino que trabajó en radio como: guionista, productor, conductor de programas radiofónicos; en los impresos fue: director, editorialista, cronista y redactor de los medios impresos; en lo popular y alternativo motivó 
la horizontalidad para interrelacionarse con la gente de los sectores rurales y urbano-marginales; la lectura de las cartas que le enviaban y las respuestas le colocaron en un nivel distinto. Fue un interlocutor que aportó con soluciones las dificultades que le comentaban quienes le visitaban.

A finales de la década del 50 se refirió por primera vez a la alfabetización y la reforestación como dos mecanismos para construir un nuevo hombre y un mejor entorno en el que co-habiten. Y para fines educativos el prelado visitó la experiencia en Colombia de radio Sutatenza junto con otros religiosos y emprende su camino hacia la puesta en marcha de su proyecto radiofónico con el que, se estima fueron alfabetizados 18 mil campesinos indígenas; saber leer y escribir equivalía a recuperar la luz en medio de las tinieblas, volver a tener la voz perdida por siglos de silencio y a caminar hacia una nueva vida, ese proyecto es Escuelas Radiofónicas Populares del Ecuador. Y, como complemento puso en circulación el periódico Jatari Campesino (que llegó a tener un tiraje de 10 mil ejemplares), para que en el sector rural practicaran lo que habían aprendido leyendo el medio impreso, que fue bilingüe. Desde 1962 hasta 1976, tras 14 años de funcionamiento la alfabetización se convirtió en teleducación:

Los niveles de discursividad y de alocución siempre fueron directos y frontales; no se consideró a sí mismo como un gran orador, decía que huía de los micrófonos pero que cuando estaba con su pueblo no paraba de hablar porque se sentía en confianza. La clave de su éxito era la cantidad de información que tenía producto de las largas conversaciones que mantenía con la gente; tomaba apuntes en su agenda y almacenaba en su memoria para cuando llegaba la ocasión de referirse a ello.

Su vínculo y el liderazgo que ejerció en los sectores campesinos-populares, las publicaciones en las que reivindicaba los derechos del indio, el discurso revolucionario en medio de una iglesia conservadora y una sociedad en vías de desarrollo, la lucha por la organización comunitaria como protección de los derechos colectivos, la formación de religiosos nativos para atender el déficit de sacerdotes en el campo, y los centros eclesiales de base como mecanismo de organización-lucha para lo religioso-educativo, le causaron inconvenientes, como su apresamiento en agosto de 1976 por considerar estas acciones como subversivas y hasta guerrilleras.

Treinta años después de su muerte, aún continúan los estudios que ponen énfasis en la religión como un proceso de evangelización; sin embargo, desde la comunicación el camino que resta por andar es extenso y los hallazgos que se presentan en el presente trabajo ponen en evidencia un legado que, merece tomarlo en cuenta porque tiene una propuesta que puede aplicarse a lo contemporáneo para transformar la sociedad.

\section{Referencias Bibliográficas}

Bardin, L. (1986). El análisis de contenido. Madrid: Akal.
Baudrillard, J. (1984). Cultura y simulacro. Barcelona: Kairós.

Berelson, B. (1952). Content analysis in communication researches. (Glencoe III, Free Press.)

Canaval, G. (2000). El cambio social: análisis del concepto y aplicación en la investigación, educación y práctica de los profesionales de la salud. Colombia Médica, 31(1), 37-42.

Freire, P. (1976). Pedagogía del oprimido. México: Siglo XXI Editores.

García, D. (2008). Por los caminos de la educación radiofónica. (Universidad de Brasil)

Gavilanes, J. (1992). Monseñor leonidas proaño y su misión profético-liberadora en la iglesia de américa latina. FEPP. Quito.

Kirk, J., y Miller, M. (1986). Reliabilitv validily in qualitative research, new park: California: Sage, qualitative research methods series.

Kvale, S. (1961). Imerviews. aii trodllc to qllalitalive research tervieving. Sage. Londres.

López, F. (2002). El análisis de contenido como método de investigación. Revista de Educación, 4, 167-179. (Universidad de Huelva.)

M., H. (1992). Environmentalism and political participation: toward a new system of social beliefs and values. J Appl Social Psychol, 22, 657-76.

Mills, C. W. (1959). The sociological imagination. Nueva York: The Oxford University Press.

Muñoz, M. (2011). A propósito de la dialéctica concreta de herbert marcuse. Madrid, España.: Universidad Carlos III de Madrid.

Ossandon, F. (1988). Comunicación popular, alternativa y participatoria. Ediciones Ciespal. Quito.

Proaño, L. (1956). De conversación con mis hijos - la parcelación. Revista Mensaje. (Diócesis de Riobamba)

Proaño, L. (1960). De conversación con mis hijos - el ceas. Revista Mensaje. (Diócesis de Riobamba)

Proaño, L. (1974). Concientización, evangelización y política. Ediciones Sígueme. Salamanca, España.

Rizo, M. (2012). Imaginarios sobre la comunicación. algunas certezas y muchas incertidumbres en torno a los estudios de comunicación, hoy. bellaterra. Barcelona: Institut de la Comunicació, Universitat Autònoma de Barcelona.

Rizo García, M. (s.f.). Comunicación e interacción social. aportes de la comunicología al estudio de la ciudad, la identidad y la inmigración. Global Media Journal.

Serrano, M. (1982). Teoría de la comunicación. Madrid, España: Gráficas Valencia.

Ávalos, B. (2017). Comunicación contrahegemónica, ventriloquía y lenguaje de contienda en escuelas radiofónicas populares del ecuador y movimiento indígena de chimborazo 1960-1990. Descargado de https://goo.gl/TK958A 
Recibido: 30 de junio de 2018

Aceptado: 3 de septiembre de 2018

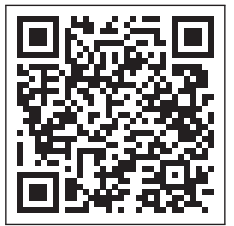


